\title{
WIIBRAGEC

\section{IMPLEMENTAÇÃO DE MEDIDAS CONTRA COVID-19 NOS CANTEIROS DA REGIÃO METROPOLITANA DE SALVADOR ${ }^{1}$}

\author{
SANTOS, Mírian Caroline Farias (1); COSTA, Dayana Bastos (2)
}

(1) Universidade Federal da Bahia, miriancfarias@gmail.com (2) Universidade Federal da Bahia, dayanabcosta@ufba.br

\begin{abstract}
RESUMO
Atualmente, o Brasil ocupa posição significativa em número de casos e óbitos no ranking mundial da COVID-19. Considerada pelo governo como atividade essencial, a indústria da construção, diante da diversidade de recomendações para o enfrentamento da doença, precisa de ações efetivas para mitigar os riscos a que os trabalhadores estão sujeitos. Assim, este trabalho tem por objetivo diagnosticar amostras de canteiros de obras na região metropolitana de Salvador-BA (RMS), analisando a evolução histórica da implementação das medidas de restrições relacionadas a COVID-19 e as dificuldades correlacionadas. Para isso, no periodo de abril a outubro de 2020, foi realizado o levantamento de dados oriundo de pesquisas de entidades setoriais, entrevistas com especialistas em segurança, especialista em gestão de obras e trabalhadores, além de visitas a canteiros de obras. Embora a priorização da retirada das pessoas do grupo de risco tivesse uma maior flexibilização ao longo dos meses, observou-se que houve também uma crescente adoção de medidas para reduzir a intensidade e duração do contato pessoal, como o escalonamento de uso de refeitório. Houve dificuldade para monitoramento e uso de correto do EPI, bem como na medição de temperatura nos canteiros.
\end{abstract}

Palavras chave: Medidas restritivas, Canteiros de obras, Dificuldades.

\begin{abstract}
Currently, Brazil occupies a significant position in the number of cases and deaths in the world ranking of COVID-19. Considered by the government as an essential activity, the construction industry needs quick actions to mitigate the biological risks to which workers are subject, due to the diversity of recommendations for facing this disease. Thus, this work aims to diagnose site samples in the metropolitan region of Salvador-BA, analyzing the historical evolution of the implementation of the measures of restrictions related to COVID-19 and the correlated difficulties. For this, in the period from April to October 2020, a survey of data from sectorial entities research was carried out, in addition to interviews with safety specialists, construction management specialists, workers, sector leaders and epidemiologists, besides visits to construction sites. Although the temperature measurement and prioritizing the removal of people from the risk group had greater flexibility over the months, there was an increasing adoption of measures to reduce the intensity and duration of personal contact, such as rotation the use of refectory. There was difficulty in maintaining social distance and in controlling the symptoms of employees.
\end{abstract}

Keywords: Restrictive measures, COVID-19, Construction sites.

\section{INTRODUÇ̃̃̃}

A COVID-19, uma doença respiratória causada pelo vírus SARS-CoV-2, vem se espalhando rapidamente de pessoa para pessoa, e em todo o mundo há uma preocupação em limitar a sua propagação e evitar consequências catastróficas. Contudo, apesar das recomendações de minimização das interações humanas por meio do distanciamento

\footnotetext{
${ }^{1}$ SANTOS, M. C. F.; COSTA, D. B. Implementação de medidas contra COVID-19 nos canteiros da Região Metropolitana de Salvador. In: SIMPÓSIO BRASILEIRO DE GESTÃO E ECONOMIA DA CONSTRUÇÃO, 12., 2021, Maceió, Alagoas. Anais[...] Porto Alegre: ANTAC, 2021. p.1-8. Disponível em: https://eventos.antac.org.br/index.php/sibragec/article/view/671. Acesso em: 2 out. 2021.
} 
social, algumas atividades, tal como a construção, que desempenham um papel fundamental na sociedade são impossíveis de serem realizadas online (ARAYA, 2021).

Esta impossibilidade de trabalho remoto tem gerado impactos nos canteiros como: absenteísmo, interrupção do fornecimento / entrega de materiais (OSHA, 2020), redução no número de trabalhadores permitidos dentro do canteiro e alteração na sua forma de trabalho, bem como impactos na forma como os gestores organizam a força de trabalho (ARAYA, 2021). E como diferentes países, estados e municípios vem adotando medidas de mitigação de risco variadas para combater a propagação da COVID-19 (BRUIN et al., 2020), os impactos do coronavírus no setor de construção podem variar, uma vez que os governos estão fornecendo recomendações com base no número de casos em seus respectivos estados (KILLOUGH 2020), na estrutura da sociedade e dos sistemas de saúde (BRUIN et al., 2020).

No Brasil, o Supremo Tribunal Federal decidiu pela autonomia dos estados e municípios ante as medidas de controle da propagação da COVID-19. Em Salvador foram expedidos diversos decretos, alguns determinando protocolos gerais e específicos para atividades da construção civil (SUPREMO TRIBUNAL FEDERAL, 2020). Além dessas medidas governamentais, também houve recomendações das entidades setoriais como o Sinduscon-BA e o SESI Saúde-BA (SINDUSCON-BA, 2020).

Diante da diversidade de recomendações, da escassez de estudos sobre o tema, e da singularidade da pandemia de COVID-19, é crucial compreender os problemas associados ao coronavírus para refinar as recomendações a serem implementadas. Portanto, esse trabalho tem por objetivo analisar a implementação das restrições referentes a COVID-19, a partir de uma amostra de canteiros de obras da RMS coletadas no período de abril a outubro de 2020, analisando a evolução da implementação das medidas de restrições relacionadas a COVID-19 e as dificuldades relacionadas.

\section{MÉTODO}

Para este estudo foi adotada a abordagem de pesquisa qualitativa. Para isso, primeiramente, procurou-se fazer uma revisão bibliográfica sobre as recomendações dos órgãos mundiais, federais, estaduais, municipais e setoriais aplicadas à construção civil, em seguida foi realizado um diagnóstico de uma amostra de obras nos canteiros da RMS através do levantamento de dados primários e secundários.

Para levantamento das medidas utilizou-se como referência o Ofício circular SEI $\mathrm{n}^{\mathrm{o}}$ 1247/2020/ME 14 de abril de 2020 do Ministério da Economia e os Decretos de Salvador $\mathrm{N}^{\mathrm{o}} 32.461$ de 01 de junho de 2020 e $\mathrm{N}^{\mathrm{o}} 32.675$ de 08 de agosto de 2020 , além do Guia para prevenção da COVID-19 na construção civil elaborado pelo SINDUSCON / SESI BA.

Como fonte de dados secundários, foram levantados dados oriundos de pesquisas realizadas pelo Sinduscon-BA e das visitas aos canteiros realizadas pelo SESI-BA em parceria com o Sinduscon, no projeto Blitz COVID-19. Grande parte dos dados do Sinduscon-BA estavam em formato de gráficos de barras, sendo necessário inferir algumas respostas por meio de interpretação. Já os dados da Blitz COVID-19 foram disponibilizados em forma de planilhas com as perguntas, respostas (sim ou não) e, em alguns casos, com um breve relato sobre as fontes de evidência que comprovavam a resposta do participante. Para auxiliar a interpretação das fontes de evidência em cada questão, quando possível, esses relatos eram agrupados por evidências similares compondo um único tipo de resposta. O Quadro 1 sumariza os dados secundários.

Para coleta de dados primários, foi realizada a seleção das empresas participantes baseada em uma lista com o contato de 25 empresas da RMS com obras em andamento, 
disponibilizada pelo Sinduscon-BA. No total, dez empresas aceitaram participar da pesquisa. O perfil das 10 obras estudadas é apresentado no Quadro 2.

Quadro 1 - Resumo dos dados secundários

\begin{tabular}{|l|l|l|}
\hline Características & \multicolumn{1}{|c|}{$\begin{array}{c}\text { Monitoramento do } \\
\text { Sinduscon-BA }\end{array}$} & \multicolumn{1}{c|}{ Blitz COVID-19 } \\
\hline Período & Abril a julho/2020 & Abril a maio/2020 \\
\hline Tipo de dados & Gráficos e tópicos & Planilha de dados qualitativos \\
\hline & $27 / 04 / 2020-53$ obras & \\
Participantes & $11 / 05 / 2020-58$ obras & Abril -47 obras \\
& $10 / 06 / 2020-48$ obras & Maio - 26 obras \\
& $25 / 07 / 2020-38$ obras & \\
\hline Coleta de dados & Questionário online & Visitas \\
\hline $\mathbf{N}^{0}$ de questões & 9 & 25 \\
\hline
\end{tabular}

Fonte: Autoras

Quadro 2 - Perfil das obras visitadas

\begin{tabular}{|r|l|l|l|r|r|l|}
\hline Obra & \multicolumn{1}{|c|}{$\begin{array}{c}\text { Sistema } \\
\text { Construtivo* }\end{array}$} & Segmento & $\begin{array}{l}\text { Tipo- } \\
\text { logia }\end{array}$ & $\begin{array}{c}\text { Área } \\
\text { Construí } \\
-\mathbf{d a}\left(\mathbf{m}^{2}\right)\end{array}$ & $\begin{array}{c}\text { No } \\
\text { Funcio } \\
- \text { nários }\end{array}$ & \multicolumn{1}{|c|}{ Etapa da obra } \\
\hline $\mathbf{1}$ & Parede de concreto & Residencial & $\begin{array}{l}\text { Vert./ } \\
\text { Horiz } \\
\text { - }\end{array}$ & 16916 & 130 & $\begin{array}{l}\text { Estrutura; Vedação; } \\
\text { Cobertura; } \\
\text { Acabamentos finais }\end{array}$ \\
\hline $\mathbf{2}$ & Parede de concreto & Residencial & Vert. & 36767 & 84 & Fundações; Estrutura \\
\hline $\mathbf{3}$ & Alv. estrutural & $\begin{array}{l}\text { Residencial } \\
\text { / Escolar }\end{array}$ & Vert. & 2140 & 15 & Acabamentos finais \\
\hline $\mathbf{4}$ & $\begin{array}{l}\text { CA, alvenaria de } \\
\text { vedação e drywall }\end{array}$ & Residencial & Vert. & 64992 & 280 & Estrutura; Vedação \\
\hline $\mathbf{5}$ & $\begin{array}{l}\text { CA, alvenaria de } \\
\text { vedação e drywall }\end{array}$ & Residencial & Vert. & 22604 & 110 & Acabamentos finais \\
\hline $\mathbf{6}$ & $\begin{array}{l}\text { CA, alvenaria de } \\
\text { vedação e drywall }\end{array}$ & Residencial & Vert. & 47939 & 200 & Estrutura \\
\hline $\mathbf{7}$ & $\begin{array}{l}\text { CA, alvenaria de } \\
\text { vedação e drywall }\end{array}$ & Residencial & Vert. & - & 46 & Estrutura \\
\hline $\mathbf{8}$ & Reforma de fachada & Hospitalar & Vert. & 2000 & 30 & Acabamentos finais \\
\hline $\mathbf{9}$ & $\begin{array}{l}\text { CA e alvenaria de } \\
\text { vedação }\end{array}$ & Residencial & Vert. & 12284 & 60 & Estrutura \\
\hline $\mathbf{1 0}$ & $\begin{array}{l}\text { CA, alvenaria de } \\
\text { vedação e drywall }\end{array}$ & Residencial & Vert. & 9966 & 75 & $\begin{array}{l}\text { Esquadrias; Instalações; } \\
\text { Acabamentos finais }\end{array}$ \\
\hline
\end{tabular}

*CA- concreto armado

Fonte: Autoras

Em cada obra foram realizadas entrevistas, que contou com duas partes: uma sobre questões de segurança, respondidas por técnicos ou engenheiros de segurança (aqui chamados de especialistas em segurança), e outra sobre questões de produção, respondidas por engenheiros civis responsáveis pelas obras (aqui chamados de gestores das obras). Dessas obras, seis aceitaram também a presença da equipe de pesquisadores em visita aos canteiros para verificação das medidas e entrevista com trabalhadores.

Foram entrevistados 10 especialistas em segurança e 10 gestores de obra, um de cada obra, para responderem questões sobre os procedimentos de saúde e segurança adotados nos canteiros e as medidas e impactos na produção, respectivamente. Durante as visitas aos canteiros, foram usados questionários para inquirir os trabalhadores a sua percepção das medidas de saúde e segurança adotadas no seu ambiente de trabalho. Foram entrevistados 2 trabalhadores por visita, totalizando 12 trabalhadores entrevistados. $\mathrm{O}$ perfil de todos os entrevistados é apresentado no Quadro 3.

Todas as entrevistas foram compostas por um roteiro de questões abertas, em que os entrevistados respondiam livremente a cada uma dessas questões por videochamada ou por contato telefônico. Já as visitas duraram em torno de $30 \mathrm{~min}$ e foi utilizado um checklist para auxiliar na verificação das medidas adotadas nas obras. 
Quadro 3- Perfil dos Entrevistados e tempo das entrevistas por obra visitada

\begin{tabular}{|l|l|c|l|c|l|l|}
\hline Obra & $\begin{array}{l}\text { Entrevistado } \\
\text { - Segurança }\end{array}$ & $\begin{array}{l}\text { Tempo } \\
\text { (min) }\end{array}$ & $\begin{array}{l}\text { Entrevistado - } \\
\text { Produção }\end{array}$ & $\begin{array}{l}\text { Tempo } \\
\text { (min) }\end{array}$ & $\begin{array}{l}\text { Serviço - } \\
\text { Trabalhador A }\end{array}$ & $\begin{array}{l}\text { Serviço - } \\
\text { Trabalhador B }\end{array}$ \\
\hline $\mathbf{1}$ & $\begin{array}{l}\text { Téc. } \\
\text { Segurança }\end{array}$ & 26 & $\begin{array}{l}\text { Eng. Civil - } \\
\text { Gestor de obra }\end{array}$ & 15 & Fiscalização & Pedreiro \\
\hline $\mathbf{2}$ & $\begin{array}{l}\text { Téc. } \\
\text { Segurança }\end{array}$ & 18 & $\begin{array}{l}\text { Eng. Civil - } \\
\text { Gestor de obra }\end{array}$ & 6 & $\begin{array}{l}\text { Instalações } \\
\text { elétricas }\end{array}$ & $\begin{array}{l}\text { Encarregado } \\
\text { geral }\end{array}$ \\
\hline $\mathbf{3}$ & $\begin{array}{l}\text { Eng. Civil - } \\
\text { Gestor de obra }\end{array}$ & 16 & $\begin{array}{l}\text { Eng. Civil - } \\
\text { Gestor de obra }\end{array}$ & 18 & - & - \\
\hline $\mathbf{4}$ & $\begin{array}{l}\text { Eng. } \\
\text { Segurança }\end{array}$ & 45 & $\begin{array}{l}\text { Eng. Civil - } \\
\text { Gestor de obra }\end{array}$ & 9 & Sinaleiro & $\begin{array}{l}\text { Controle de } \\
\text { qualidade }\end{array}$ \\
\hline $\mathbf{5}$ & $\begin{array}{l}\text { Téc. } \\
\text { Segurança }\end{array}$ & 17 & $\begin{array}{l}\text { Eng. Civil - } \\
\text { Gestor de obra }\end{array}$ & 6 & - & - \\
\hline $\mathbf{6}$ & $\begin{array}{l}\text { Téc. } \\
\text { Segurança }\end{array}$ & 27 & $\begin{array}{l}\text { Eng. Civil - } \\
\text { Gestor de obra }\end{array}$ & 12 & $\begin{array}{l}\text { Chumbamento } \\
\text { de tubulações }\end{array}$ & $\begin{array}{l}\text { Instalação de } \\
\text { gás }\end{array}$ \\
\hline $\mathbf{7}$ & $\begin{array}{l}\text { Téc. } \\
\text { Segurança }\end{array}$ & 25 & $\begin{array}{l}\text { Eng. Civil - } \\
\text { Gestor de obra }\end{array}$ & 4 & Carpinteiro & $\begin{array}{l}\text { Encarregado } \\
\text { geral }\end{array}$ \\
\hline $\mathbf{8}$ & $\begin{array}{l}\text { Téc. } \\
\text { Segurança }\end{array}$ & 12 & $\begin{array}{l}\text { Coordenador } \\
\text { de obras }\end{array}$ & 17 & $\begin{array}{l}\text { Instalação de ar- } \\
\text { condicionado }\end{array}$ & $\begin{array}{l}\text { Emassamento de } \\
\text { fachada }\end{array}$ \\
\hline $\mathbf{9}$ & $\begin{array}{l}\text { Téc. } \\
\text { Segurança }\end{array}$ & 23 & $\begin{array}{l}\text { Coordenador } \\
\text { de obras }\end{array}$ & 22 & - & - \\
\hline $\mathbf{1 0}$ & $\begin{array}{l}\text { Téc. } \\
\text { Segurança }\end{array}$ & 20 & $\begin{array}{l}\text { Diretor de } \\
\text { obras }\end{array}$ & 7 & - & - \\
\hline
\end{tabular}

Fonte: Autoras

\section{RESULTADOS}

Após a revisão bibliográfica obteve-se um total de 39 medidas recomendadas pelo Ministério da Economia, Prefeitura de Salvador e pelos órgãos setoriais SINDUSCON / SESI - BA. Dentre elas destacam-se as medidas que tiveram dados levantados nos estudos da Blitz COVID-19, Monitoramento Sinduscon-BA e no presente estudo primário, são elas: (a) Priorizar o afastamento imediato de pessoas no grupo de risco, (b) Medição de temperatura, (c) Escalonamento de horários, (d) Treinar, registrar e monitorar o uso de EPI, e (e) Elaborar um plano de contingência e Adotar medidas para diminuir a intensidade e a duração do contato pessoal entre trabalhadores.

As Figuras de 1 a 5 apresentam a evolução do número de casos, calculado pela média de sete dias, na Bahia e em Salvador utilizando os dados disponibilizados na plataforma GEOCOVID-19, no período de abril a outubro/2020, juntamente com as cinco medidas identificadas em comum nos três estudos analisados.

Ao se analisar o gráfico juntamente com os dados de cada estudo presentes nas caixas de textos, observa-se que ao longo dos meses houve uma crescente adoção de medição de temperatura nos canteiros (Figura 1). Logo no início da pandemia, em abril, a aferição da temperatura nos canteiros estava em torno de $74 \%$ e $63 \%$, conforme dados da Blitz COVID-19 e do Monitoramento Sinduscon-BA, respectivamente. Isso porque algumas empresas tiveram dificuldade na aquisição de termômetros devido a falta do equipamento no mercado. Nos meses seguintes esse percentual foi aumentando, em ambas as pesquisas citadas anteriormente, e nos meses de setembro a outubro, durante a presente pesquisa, $90 \%$ especialistas em segurança informaram que estavam utilizando termômetro no canteiro. Contudo, nesse mesmo período, a aferição da temperatura para acesso da equipe de pesquisadores aos canteiros ocorreu somente em 33\% das obras visitadas.

Dentre as medidas adotadas para evitar aglomerações, o escalonamento de turnos (Figura 2) foi adotado de forma crescente, pela maioria das obras, desde abril até outubro. $O$ trabalho em turnos alternados variou, na pesquisa do Monitoramento Sinduscon-BA, entre $55 \%, 48 \%, 90 \%$ e $80 \%$, nos meses de abril, maio, junho e julho, respectivamente. Já o escalonamento para uso dos refeitórios e vestiários, segundo dados da Blitz COVID- 
19 cresceu de $28 \%$, em abril, para $54 \%$ das obras, em maio. No período de setembro a outubro, conforme presente pesquisa, $100 \%$ dos entrevistados confirmaram tal prática nos canteiros. Também foi citado na pesquisa da Blitz COVID-19, o escalonamento de entradas e saídas, o que for confirmado por $33 \%$ dos trabalhadores da presente pesquisa.

Figura 1 - Evolução dos casos de COVID-19 x Medição de temperatura

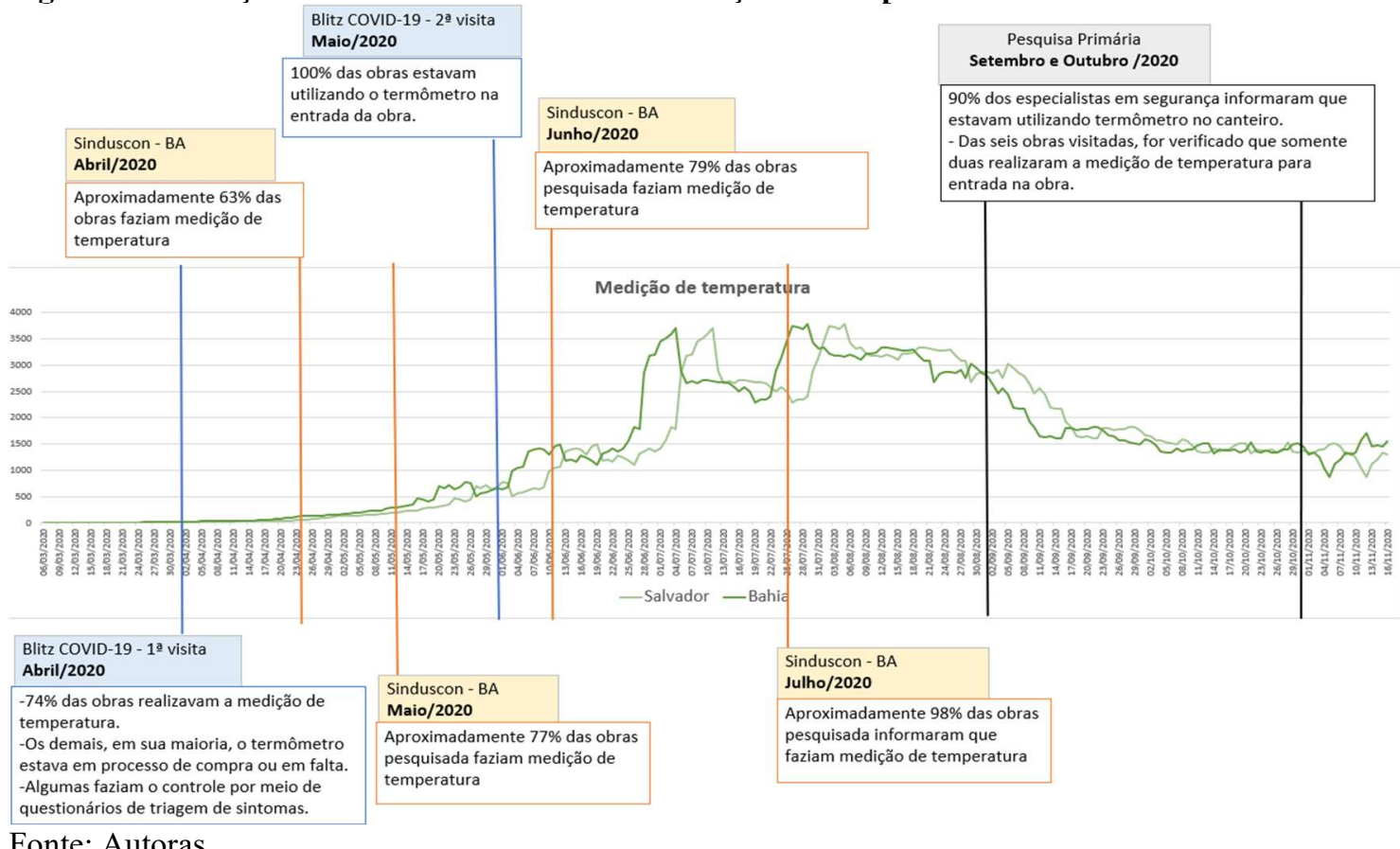

Fonte: Autoras

Figura 2- Evolução dos casos de COVID-19 x Escalonamento de horários

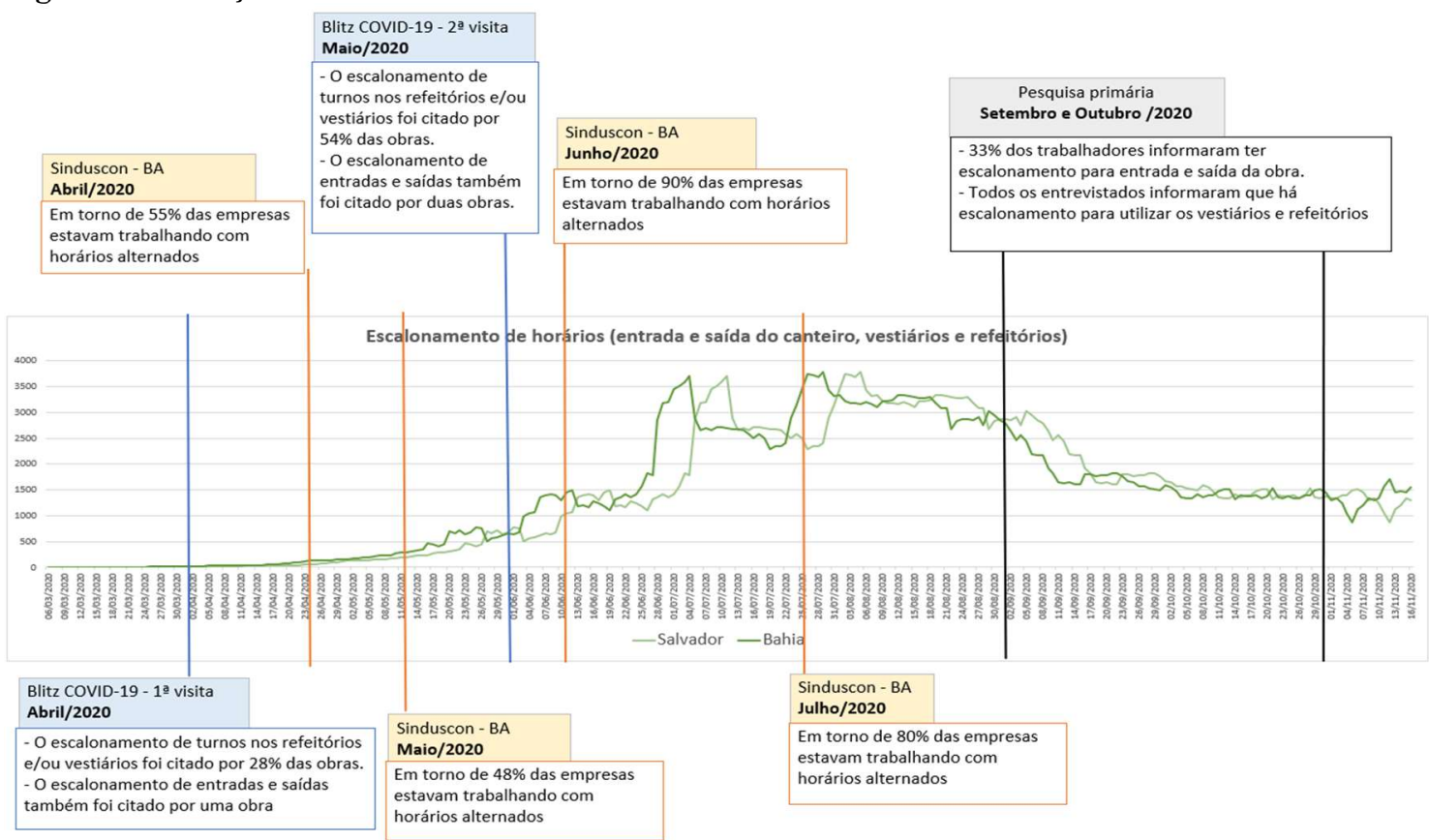

Fonte: Autoras

Observa-se também que no mês de abril de 2020 mais de $90 \%$ dos entrevistados nos estudos da Blitz COVID-19 e do Monitoramento Sinduscon-BA priorizaram o afastamento imediato de pessoas no grupo de risco (Figura 3). No mês de maio deste mesmo ano, esse percentual se manteve em torno de $88 \%$ nas obras, segundo a Blitz COVID-19. Com percentuais de $92 \%, 88 \%$, e $91 \%$, nos meses de maio, junho e julho de 2020, respectivamente, conforme dados do Monitoramento Sinduscon-BA. Já nos meses de setembro a outubro de 2020 , o percentual estava em torno de $60 \%$, de acordo com o presente estudo. 
Figura 3- Evolução dos casos de COVID-19 x Priorização do afastamento de pessoas no grupo de risco

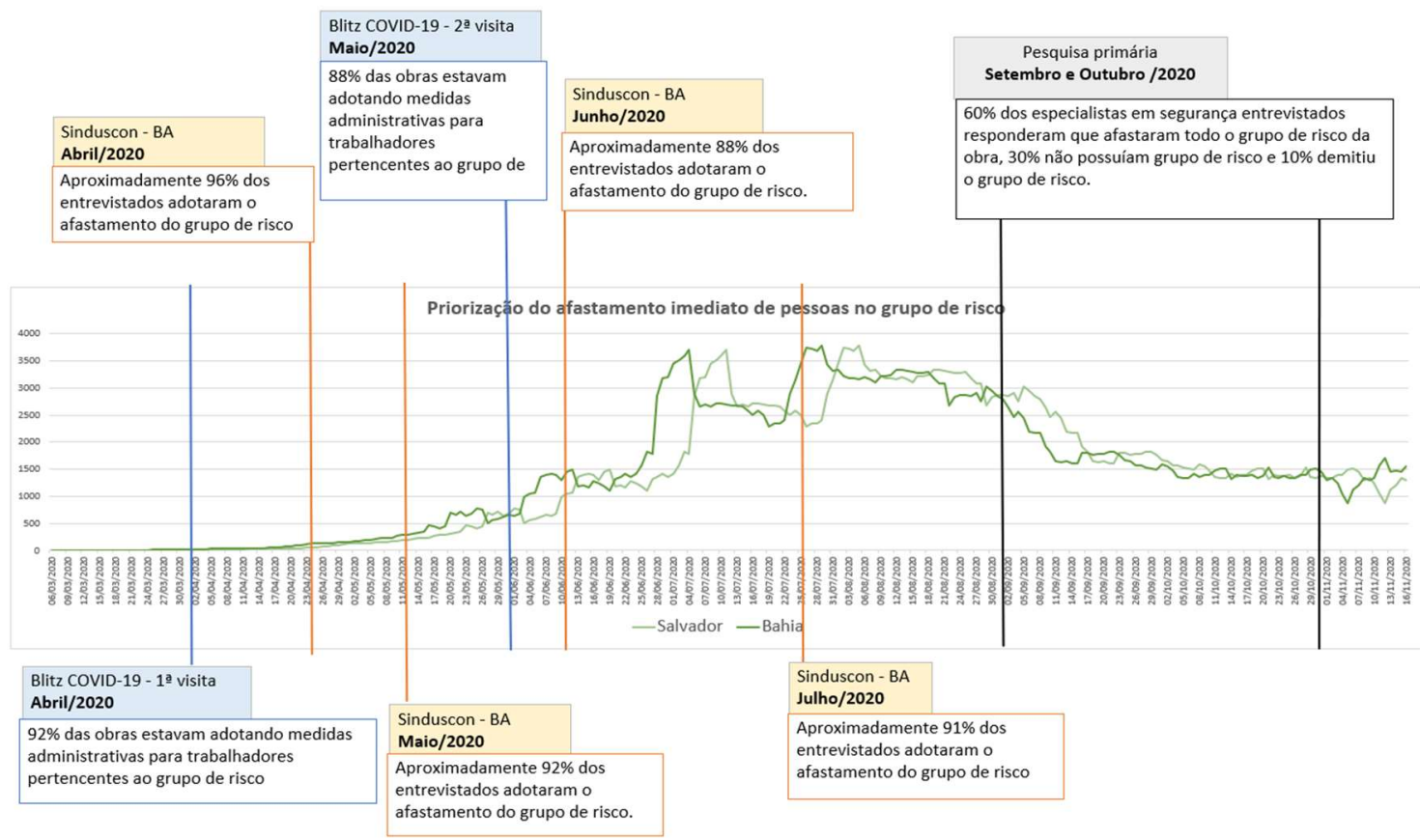

Fonte: Autoras

Com relação ao treino, registro e monitoramento do uso de EPI (Figura 4), no período de abril a junho de 2020, na pesquisa do Monitoramento Sinduscon-BA, 100\% dos entrevistados informaram que as empresas realizaram treinamento específico para prevenção da COVID-19. Além disso, conforme dados da Blitz COVID-19, na maioria das obras foi observado que os trabalhadores faziam uso do EPI, onde $45 \%$ e $42 \%$ desses entrevistados, em abril e maio, respectivamente, realizaram também o treinamento para uso correto do EPI. Já no período de setembro a outubro, $70 \%$ dos entrevistados, durante a presente pesquisa, relataram que realizaram treinamento específico para sobre uso de EPI. Apesar das dificuldades de conscientização da mão de obra, de forma geral, corrigiam as não conformidades encontradas no canteiro com conversas informais com os trabalhadores.

Figura 4- Evolução dos casos de COVID-19 x Treinamento, registro e monitoramento do uso de EPI

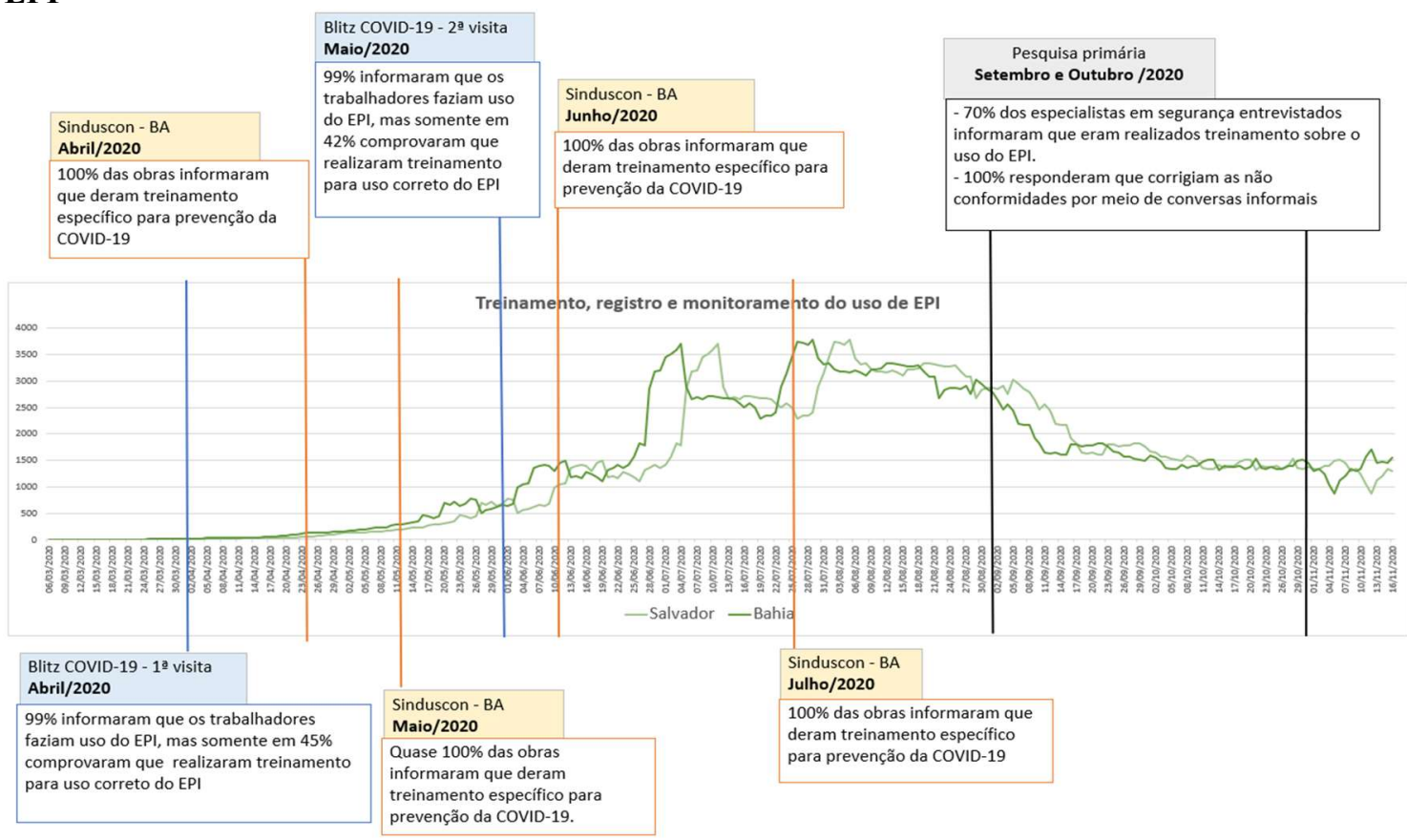

Fonte: Autoras 
Por fim, ao longo dos meses, observou-se um comprometimento de todas as empresas em elaborar um plano de contingência para controle de propagação da COVID-19, principalmente por meio da adoção de diversas medidas para diminuir a intensidade e a duração do contato pessoal entre trabalhadores (Figura 5). Dentre as medidas, destacamse a instalação de estações para higienização, mudanças no layout do canteiro, demarcação para distanciamento social, ausência ou redução das reuniões presenciais, e identificação de funções que podem efetuar suas atividades por meio de teletrabalho.

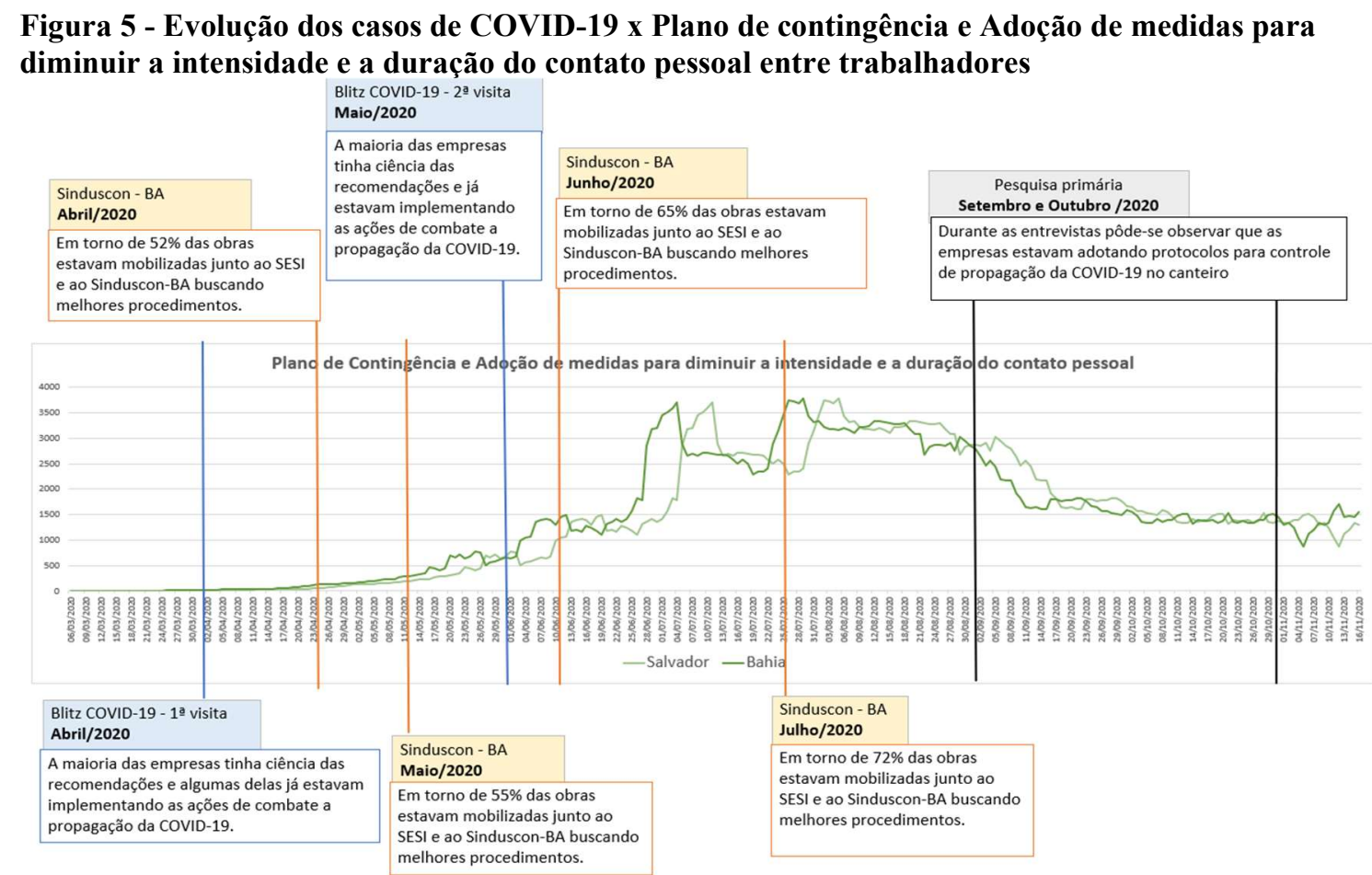

Fonte: Autoras

\section{DISCUSSÃO}

Com relação as medidas estudadas, como não foi possível verificar a total implementação da medição da temperatura durante as visitas ao canteiro, infere-se que houve um afrouxamento da implementação dessa medida. Além disso, como a alteração da temperatura é apenas um dos possíveis sintomas da COVID-19, recomenda-se a aplicação de questionários para verificação de sintomas, bem como a criação de protocolos de testagem periódica.

A adoção do escalonamento deve ocorrer não semente para uso de vestiários e refeitórios, mas para entrada e saída na obra, pois, segundo os trabalhadores, o registro de ponto na entrada e na saída eram locais de aglomeração frequente.

Embora o afastamento de pessoas no grupo de risco tenha sido implementado no início da pandemia e flexibilizado após o primeiro pico da COVID-19 em Salvador, sabe-se que o risco de contaminação é aumentado com o aumento do tempo de exposição. Assim, esse grupo ainda continua exposto e suscetível a contaminação. Se a função do trabalhador possibilitar o afastamento, pode-se optar por teletrabalho. Já para outras funções pode-se optar por redução da carga horária de trabalho para reduzir o tempo de exposição.

Apesar do uso das máscaras ser uma política adotada pelas empresas, a conscientização dos trabalhadores para uso das máscaras foi uma dificuldade recorrente. Portanto, o treino da mão de obra quanto ao uso correto do EPI pode não estar sendo suficiente para corrigir esse comportamento, sendo necessário uma fiscalização mais rigorosa; ações corretivas, 
como treinamento de reciclagem; ou ações de incentivo, como a nomeação de funcionários exemplares.

\section{CONSIDERAÇÕES FINAIS}

Este artigo apresentou um panorama da evolução da implementação de algumas das medidas de restrição relacionadas a COVID-19 nos canteiros de obra na RMS, identificando dificuldades e propondo recomendações para refinamento das mesmas.

Foi observado que as empresas elaboraram planos de contingência para evitar a proliferação da doença nos canteiros, destacando-se as medidas que foram progressivamente adotadas como o escalonamento para uso de vestiários e refeitórios e $\mathrm{o}$ treinamento para uso correto dos EPIs. Sendo que para esta última houve relatos de dificuldades na conscientização dos trabalhadores. Já as medidas com problemas associados à sua implementação foram a priorização do afastamento de pessoas no grupo de risco e a medição de temperatura.

As principais limitações deste estudo foram o número reduzido de obras participantes quando comparado ao número de empresas com obras em andamento no período da pesquisa, e o tempo das visitas que foi limitado, uma vez que se buscava reduzir o risco de contaminação dos pesquisadores. Assim, não foi possível verificar toda a rotina de prevenção a COVID-19 nos canteiros durante os expedientes de trabalho. Em trabalhos futuros pode-se avaliar os tipos de treinamentos dados aos trabalhadores, sua periodicidade, e a percepção dos trabalhadores sobre esses treinamentos, assim será possível analisar se a recorrência no uso incorreto dos EPI é devido a qualidade dos treinamentos ou ao comportamento voluntário dos trabalhadores.

\section{REFERÊNCIAS}

ARAYA, F. Modeling the spread of COVID-19 on construction workers: An agentbased approach. Safety Science, v. 133, 2021. doi: 10.1016/j.ssci.2020.105022

BRUIN, Y. et al. Initial impacts of global risk mitigation measures taken during the combatting of the COVID-19 pandemic. Safety Science, v. 128, 2020. doi:

10.1016/j.ssci.2020.104773

KILLOUGH, D. How to prepare for coronavirus impact on the construction supply chain. Levelset, 2020. Disponível em: https://www.levelset.com/blog/how-to-preparefor-coronavirus-impact-on-the-construction-supply-chain/. Acesso em: 20 mar. 2021

OCCUPATIONAL SAFETY AND HEALTH (OSHA). Guidance on Preparing Workplaces for COVID-19. Disponível em: https://www.osha.gov/Publications/OSHA3990.pdf. Acesso em: 03 dez. 2020.

SESI; SINDUSCON-BA. Guia para prevenção da COVID-19 na Indústria da Construção Civil. Disponível em: http://sesi.fieb.org.br/midia/2020/6/crop_37e754837a82-44dc-9953-df95dde7de03.pdf. Acesso em: 17 de dezembro de 2020.

SUPREMO TRIBUNAL FEDERAL. STF reconhece competência concorrente de estados, DF, municípios e União no combate à COVID-19. Disponível em: http://www.stf.jus.br/portal/cms/verNoticiaDetalhe.asp?idConteudo=441447. Acesso em: 03 de março de 2021.

\section{AGRADECIMENTOS}

Ao CNPq, pelo apoio recebido. 